\title{
LOS NOVENTA EN AMÉRICA LATINA: ¿LA DÉCADA DE LAS OPORTUNIDADES O DE LAS QUIMERAS?
}

\author{
Salvador Martí i Puig*
}

Fecha de recepción: abril 2000

Fecha de aceptación y versión final: septiembre 2000

\begin{abstract}
Resumen: El presente artículo pretende esbozar una mirada crítica de lo acontecido en América Latina, a nivel político, durante los años noventa con el afán de responder porqué a finales de la década se desvaneció el entusiasmo y las espectativas con que ésta empezó. Para ello el primer epígrafe da cuenta de la reaparición del fenómeno populista y la constante inestabilidad que caracterizó a los países de la región. Posteriormente se pasa a analizar el carácter de los regímenes democráticos resultantes de los procesos de transición desde sistemas autocráticos y el impacto social de las políticas económicas de cuño liberal que aplicaron todas y cada una de las administraciones latinoamericanas. Después se debate sobre el fenómeno recurrente de la violencia en la arena política y social, y sus múltiples formas (desde los conflictos armados hasta la delincuencia común), y finalmente, se concluye con el intento de ubicar cuál es la posición y el espacio de los ciudadanos en estos regímenes que dicen basar su legitimidad en el voto popular y el consenso.
\end{abstract}

Palabras clave: democracia, procesos de cambio político, neopopulismo, crisis política e inestabilidad institucional, América Latina, neoliberalismo.

\begin{abstract}
This article critically overviews the main political events that have been taking place throughout the 90s with the aim to respond why is it that the enthusiasm and expectations with which the decade started vanished at the end. With that purpose, the first part of this work gives account of the re-emergence of populism and the unending instability that characterized the countries of the region. Subsequently, the character of the democratic regimes resulting from the transition processes and the social impact of the economic policies with neoliberal leanings applied by every single Latin American government, will be analyzed. Subsequent to the debate over the recurrent phenomenon of violence in the social and political arenas, in its multiple forms (from the armed conflicts to the common delinquency), the article finally concludes with an intent to locate the spaces and positions of the citizens of these regimes that say to ground their legitimacy on popular vote and consensus.
\end{abstract}

Key words: Democracy, Institutional Changes, Neopopulism, Political Crisis, Political Inestability, Latin America, Neoliberalism.

\section{1. ¿OPTIMISMO DEMOCRÁTICO O RETÓRICA OFICIALISTA?}

A inicios de la década de los noventa, en la Cumbre de las Américas realizada en Miami, William Clinton celebró que el continente americano (y dentro de éste América Latina) era el único del globo donde todos los países -con las notables exepciones de las islas de Cuba y Haití- gozaban de regímenes donde sus autoridades habían sido designadas por sufragio universal a través de comicios razonablemente limpios.

Un paisaje como el descrito difícilmente hubiera sido imaginado, ni por parte de los más optimistas, pocos lustros antes. Y es que, efectivamente, la ola de transiciones desde dictaduras hacia regímenes liberal-democráticos (iniciada a partir de inicios de los ochenta en Argentina y completada a inicios de los noventa en Chile) pilló por sorpresa a la mayor parte de científicos sociales -tal como lo exponen O’Donnell,
Schmitter y Whitehead (1986) al presentar su reflexión colectiva sobre las transiciones desde gobiernos autoritarios-.

Hasta la fecha todas las teorías elaboradas sobre los “cambios de regímenes" se habían centrado en el estudio de determinados factores (la cultura política, la modernización económica, la dependencia de las economías) y su plausible cambio (Karl,1995). En ese entonces los estudiosos exponían que si estos tres factores mutaban, también podrían hacerlo los regímenes, dándose la posibilidad de que aparecieran sistemas democráticos. Ciertamente, la quiebra de las dictaduras latinoamericanas no vino acompañada de ninguna transformación -en el sentido positivo- de los "factores" en cuestión: las experiencias represivas y autoritarias no dejaron ningún tipo de "cultura cívica", las

Profesor del Ciencia Política de la Universidad Autónoma de Barcelona.凶salvador.marti@uab.es 
políticas económicas y sociales implementadas durante los ochenta no conllevaron un crecimiento económico equilibrado ni equitativo, y los países latinoamericanos no dejaron de mantener relaciones económicas y políticas subordinadas con respecto a los "países desarrollados".

Fueron dos fenómenos -uno de naturaleza internacional y otro doméstico- los que, a partir de los noventa, transformaron el contexto político del subcontinente. A saber, por un lado, la aparición de un mundo unipolar donde desaparecía la supuesta "amenaza soviética" (y, con ella, la política contrainsurgente promovida por la administración norteamericana), y por otro, la profunda deslegitimación (por su ineficiencia y por sus costes morales y sociales) de los regímes de seguridad nacional que habían imperado en casi la totalidad de los países latinoamericanos (Rouquié,1984)-con las excepciones del régimen corporativo mexicano, las democracias limitadas y turnistas de Colombia y Venezuela (Peeler,1992), la estable Costa Rica (Rovira Mas,1988), y las experiencias revolucionarias de Cuba y Nicaragua.

Así las cosas, a inicios de los noventa, el optimismo imperaba: la democracia era el único desenlace posible (Huntington,1991). Parecía que, finalmente, después de tantos años de conculcación de libertades y derechos, los habitantes del subcontinente gozarían de un orden político respetuoso y conforme con la legalidad emanada de las urnas. En ese contexto hubo incluso quien proclamó el fin de uno de los elementos más recurrentes en la vida pública latinoamericana: la violencia política. Se trataba, por primera vez en la historia, de la posibilidad de crear una "utopía desarmada" (Castañeda,1993).

Con estos referentes, y en medio de un mundo geopolíticamente unipolar, América Latina parecía conquistar dos de los grandes anhelos de su historia: paz y libertad. Todo ello, obviamente, anunciado a partir de una retórica de modernidad-¿posmodernidad quizás?-fácilmente percatable a través de los fastos organizados en el marco de la Exposición Universal de Sevilla celebrada durante el año 1992 ¿Era realista este desbordante optimismo?

Esbozar una respuesta a la pregunta de si se trataba de una "nueva era” o de uno más de los recurrentes "espejismos" que la historia ha deparado a este subcontinente será el objetivo de este pequeño texto que pretende ofrecer un breve periplo por los procesos acaecidos en América Latina durante la década de los noventa. Una década que aún carece de epíteto: ¿Será la de las oportunidades? ¿O la de las quimeras?

\section{ENTRE LA INESTABILIDAD INSTITUCIONAL Y LA TENTACIÓN POPULISTA}

Si el año de la "celebración" del quinto centenario empezaba con notable optimismo en lo que respecta a la naturaleza de los regímenes, no terminaba con el mismo entusiasmo. Ya a mediados de 1992 reaparecería el viejo fantasma del golpismo en Venezuela y Perú. Fantasma que emergería posteriormente, aunque sin lograr sus objetivos, en Guatemala (el año 1994) y que se asomaría de forma intermitente en Paraguay y Honduras. Era el riesgo del resurgimiento del liderazgo político personalizado y los riesgos del neopopulismo.

En Venezuela, el 4 de febrero de 1992, un grupo de oficiales de rango intermedio del ejército, los llamados comacates (comandantes, capitanes y tenientes) autodenominados "bolivarianos" se sublevaron en varios puntos a lo largo de todo el país contra el orden constitucional -presente desde 1958- y su presidente, Carlos Andrés Pérez. Su líder, el teniente coronel Hugo Chávez Frías, se convirtió en héroe nacional: tras su aparición en la televisión -ordenando el rendimiento de sus tropas con el argumento de que "por ahora" sus objetivos no se habían logrado- obtuvo una inimaginable proyección pública. Posteriormente, el 27 de noviembre, el golpe tuvo una "segunda edición" al mando de oficiales de más alto rango. Y si bien las dos "intentonas” no cuajaron, la ciudadanía tampoco demostró entusiasmo con su débil democracia: la participación en las elecciones municipales y regionales celebradas el 6 de diciembre del mismo año no llegó al 50 por ciento, y los resultados se vieron empañados por numerosas acusaciones de fraude (Kornblith \& Levine,1994). Seis años después, en diciembre de 1998, el "golpista frustrado" Hugo Chávez ganaría cómodamente las elecciones presidenciales al frente de una coalición llamada Movimiento por la Quinta República (MVR) con un mensaje de renovación política y con el proyecto de finiquitar el orden bipartidista que durante más de tres décadas había dominado la vida política del país (González,1999).

En cuanto a Perú, fue el mismo presidente electo Alberto Fujimori quien -con el llamado autogolpe-abolió el poder legislativo y judicial. El 5 de abril de 1992 Fujimori ordenó la ocupación del Congreso por parte de las Fuerzas Armadas y destituyó a todos los jueces del país. La ruptura con el orden legal gozó de un fuerte apoyo popular entre una ciudadanía hastiada por la violencia terrorista patrocinada por la organización maoísta Sendero Luminoso y la corrupción de la clase política (Degregori,1991). La retórica de "mano dura" y "orden" formulada por el nuevo "hombre fuerte" del país consiguió un notable éxito en la celebración de los comicios, en diciembre del mismo año, para elegir una Asamblea Constituyente (el llamado Congreso Constituyente Democrático, CCD), donde la formación fujimorista obtuvo una cómoda victoria y pudo redactar una nueva carta magna a imagen y semejanza del nuevo mandatario -ver, en este sentido, el discurso pronunciado por el propio Fujimori el 28 de julio (el día de la independencia del país) de 1993 ante la CCD (Starn, Degregori y Kirk,1995: 438-445). Posteriormente, en 1995, Alberto Fujimori volvería a ganar las elecciones presidenciales por una amplia mayoría frente a una candidatura unitaria liderada por el ex-presidente de la Naciones Unidas Pérez de Cuéllar. Las repetidas victorias -en elecciones municipales y legislativas- de Fujimori han sido interpretadas como el reconocimiento de grandes sectores del electorado a su política de estabilización monetaria, a la capacidad de asertar golpes definitivos a Sendero Luminoso y a su discurso populista (Kay,1995). Por todo ello, a pesar de las concurridas protestas y la prohibición legal (referendada por el Tribunal Constitucional en 1997) de que Fujimori concurriera al ruedo electoral para un ejercer tercer mandato en los comicios del año 2000, éste 
volvió a presentarse en medio de un clima tenso y plagado de irregularidades en el que la oposición (bajo la una coalición llamada Perú Posible y liderada por el outsider, el Cholo Toledo) sólo se presentó en la primera vuelta, desiegitimando los comicios en los que Fujimori se adjudicó un nuevo mandato como Presidente de la República. Mandato que, a la vista de la tensión social acumulada, las presiones internacionales y la ventilación de diversos casos de corrupción que implicaban a cercanos colaboradores del Jefe de Estado, sólo se prolonga hasta el mes de abril del 2001, fecha en la que el mandatario se comprometió a celebrar nuevas elecciones legislativas y presidenciales en las que no va a presentarse.

En cuanto a la frágil y vigilada democracia guatemalteca, 1993 fue un año lleno de incertidumbres. Con la derrota del Partido de la Democracia Cristiana (formación artífice, junto a los militares y la administración norteamericana, del proceso de transición (Torres-Rivas,1989) y la victoria de una formación de nuevo cuño liderada por el evangelista Jorge Serrano Elías, las tensiones en el seno de la sociedad se incrementaron. A pesar de ello, en ese contexto, la pretensión de Serrano de emular a su homólogo peruano fracasó. El intento de "autogolpe" acaecido en 1993 se vino abajo ante la gran movilización ciudadana, la indecisión de las elites tradicionales y las presiones internacionales a favor del mantenimiento del orden constitucional. Serrano fue sustituido por el constitucionalista Ramiro de León Carpio. Pero en esas fechas el régimen guatemalteco tendría aún que superar múltiples retos, la mayoría de ellos relacionados con la permanencia de "enclaves autoritarios" y el respeto de los derechos humanos (Torres-Rivas,1998b). Y si bien algunos de ellos se solucionaron de forma satisfactoria -como el de la firma definitiva de la paz entre las guerrillas agrupadas en la Unión Revolucionaria Nacional Guatemalteca (URNG) y el gobierno liderado por el conservador Álvaro Arzú en diciembre de 1996 (Font,1996)- las amenazas que suponen la impunidad y la proyección de fuerzas políticas reaccionarias vinculadas al antiguo dictador Efraín Ríos Montt parecen poner en peligro la misma existencia del sistema democrático. La victoria del candidato del FRG a la presidencia de la República abre, una vez más, múltiples temores.

Fue también en el año 1992 cuando se daría inicio a un nuevo ciclo de "inestabilidad institucional" en casi todos los demás países del subcontinente. En ese mismo año las acusaciones de corrupción conllevaron la destitución del primer presidente electo de la "nueva democracia" brasileña, Fernando Collor de Mello, suponiendo un fracaso moral para las tan deseadas y esperadas instituciones democráticas del país (Hagopian,1996).

Un fenómeno semejante ocurrió en Venezuela (país al que ya nos hemos referido) y en Ecuador. En Venezuela el segundo mandato del presidente Carlos Andrés Pérez fue interrumpido a causa de su implicación en presuntos desvíos de fondos públicos en 1993. Así, por primera vez en los 35 años de estabilidad democrática, la Corte Suprema de Justica de Venezuela -previa aprobación del Senado-interrumpió el mandato a un presidente para juzgarlo por corrupción. En cuanto a Ecuador el extravangante presidente Abdalá Bucaram Ortíz, después de una polémica ges- tión y de dedicar sus esfuerzos en veleidades lúdicas y festivas, fue destituido el 6 de febrero de 1997 por el Congreso de la República-con 44 votos contra 34- aduciendo la "incapacidad mental" del mandatario. Durante las dos semanas siguientes tres personas -Bucaram, la vice-presidenta de la República, Rosalía Arteaga, y el presidente del Congreso, Fabián Alarcón- se autoproclamaron presidentes legítimos del Ecuador (Rowland,1998). Esta crisis terminó con un referéndum celebrado en el mes de mayo, con todo, desde esa fecha el país ha experimentado numerosas manifestaciones de inestabilidad institucional y descontento popular a las que no se les ve fin, y donde destacó la movilización indígena -apoyada por rangos medios de las Fuerzas Armadasque forzó la destitución del presidente constitucional Jamil Mahuad el 21 de enero del 2000 (Burbano de Lara, 2000).

Sin la gravedad arriba expuesta, la crisis institucional también se manifestó en Nicaragua durante toda la administración de Violeta Barrios de Chamorro. En ese sexenio (1990-1996) se observó un constante bloqueo entre el legislativo y el ejecutivo hasta el punto de existir, en 1995, dos órdenes constitucionales simultáneos (Close, 1999; Marti, 1997). Por otro lado, en Colombia, durante todo el período en que gobernó el presidente liberal de Ernesto Samper (19941998), la mayor tarea de la administración fue defenderse de las acusaciones de la utilización de fondos provenientes del cartel de Cali en el financiamiento de la campaña.

Pero si un país destacó por su incapacidad de reponerse al desplome de su "credibilidad" fue México. Al terminar el 1993 el país mesoamericano parecía el alumno aven tajado del subcontinente. El sexenio liderado por Raúl Salinas de Gortari, con su ajuste económico, diversas reformas constitucionales, una notable reforma institucional y la firma del Tratado de Libre Comercio con los Estados Unidos y el Canadá dio la impresión de que México entraba al "primer mundo" -ver, en este sentido el n" XXXVI de Foro Internacional en que se realiza un balance del sexenio, o el debate que mantuvieron el mismo Salinas y Castañeda en la revista Nexos-. Sin embargo, buena parte del "prestigio acumulado" se vino abajo como un castillo de naipes, justo en el momento de brindar con champagne: el 1 de enero de 1994 un grupo de guerrilleros emascarados con pasamontañas tomaron por asalto cinco cabeceras municipales (entre ellas la colonial ciudad de San Cristóbal de las Casas) del estado sureño de Chiapas -uno de los más pobres del país-.

Sin embargo, al estancamiento del conflicto armado y la progresiva militarización de la región (Leyva y Ascencio, 1996), se le sumarían nuevos problemas. Por un lado, a un mes de la toma de posición de la presidencia por parte de Ernesto Zedillo, a inicios de 1995, la economía mexicana se desplomaría: el peso perdería, en pocos días, el 60 por ciento de su valor frente al dólar (Castañeda,1995); por otro, apareció a la luz una lúgubre trama de corrupción y asesinatos que giraba en torno a la figura del Carlos Salinas y su hermano, y que terminó adquiriendo ribetes tragicómicos -en la que participarían videntes, evasores de divisas, narcotraficantes y altos cargos del oficialista Partido Revolucionario Institucional (PRI). Posiblemente por todo ello, en las elecciones celebradas el 6 de julio de 1996, el partido oficialista mexicano sufriría su más severa derrota desde 
su existencia: perdería la mayoría absoluta en la Cámara de Diputados, y, poco después, la alcaldía de la capital y el gobierno de diversos estados. Ante tal varapalo, las reacciones en el interior del PRI no se hicieron esperar: la posibilidad de perder las elecciones presidenciales de agosto de 2000 activaron nuevamente el aparato partidario que se adelantaría al proceso electoral con una elecciones primarias que pretendían anunciar la llegada de un "nuevo PRI". A pesar de ello el día 2 de agosto supuso un punto de inflexión en la historia reciente del país: el candidato opositor Vicente Fox, arropado por el Partido de Acción Nacional (PAN), ganó la Presidencia de la República rompiendo setenta de dominio (más que hegemonía) prí́sta.

Pero no sólo en los países citados se observaron "problemas". Incluso en aquellos más "normalizados” se percibieron conductas institucionales que podrían considerarse, como mínimo, de inapropiadas. Nos referimos a las reformas de los textos constitucionales de Argentina (bajo el auspicio de Carlos Menem) y de Brasil (con Fernando Henrique Cardoso) con el objetivo de posibilitar la reelección de los presidentes en el poder; y a las tensiones generadas en Chile -por las Fuerzas Armadas y las formaciones políticas pinochetistas- a tenor de la detención, en 1998, del ex-dictador y senador vitalicio Augusto Pinochet en Londres. ¿A qué se debe tanta inestabilidad?

\section{EL CARÁCTER DE LAS NUEVAS DEMOCRACIAS}

Es difícil dar una respuesta simple a la pregunta arriba planteada, pero entre la comunidad académica, a la hora de interpretar los procesos de transiciones desde regímenes autoritarios hacia democracias en América Latina, existe un cierto consenso en reconocer-además de su diversidad interna-la presencia de diferencias respecto a los acontecidos en Europa meridional una década antes. Quizás la particularidad latinoamericana pueda observarse a partir de tres fenómenos: el punto de partida de los procesos de transición; las características del proceso de cambio; y el papel de los actores externos.

En cuanto al punto de partida, la mayoría de los procesos de "democratización" que se sucedieron en el subcontinente partieron de experiencias culturales y socio-económicas muy regresivas (Bulmer-Thomas,1998). Si se observa al legado cultural de las anteriores "experiencias autoritarias" (unas más sangrientas que otras) es fácil percatarse de su voluntad de anular cualquier manifestación democrática.

El fuerte componente represor y desmovilizador de los regímenes de seguridad nacional supuso una venganza histórica contra la anterior movilización "plebeya" y "populista” que desbordó los frágiles márgenes institucionales de los sistemas liberales preautoritarios. Así, el sistemático, continuado y profundo intento de penetrar capilarmente en la sociedad para implantar orden y autoridad despojó a sus habitantes de la condición de ciudadanos (O'Donnell, 1997: 133-145). En ese marco no hubo sólo gobiernos extremadamente despóticos, sino también convirtieron a la sociedad en un entorno acusadamente autoritario.
Por lo que hace al contexto socioeconómico, vale decir que el período en que se llevaron a cabo los procesos de transición estuvieron marcados por situaciones económicas de profunda depresión, caracterizadas por una precarización acelerada de la frágil clase media. Después de la crisis de la deuda el flujo neto de préstamos bancarios para la región se detuvo en seco, y la transferencia de capital pronto se volvió negativa. De ello, los países no sólo se vieron obligados a reducir sus importaciones y a aumentar con rapidez las exportaciones, sino a ofrecer "incentivos de precio" para que la oferta pasara del mercado interno al mundial, y a reducir la intervención del estado en la economía y a suprimir buena parte de los servicios hasta entonces prestados. A medio plazo -tal como veremos en el próximo apartado- el impacto de estas políticas, si bien resultaron algo satisfactorias a nivel macroeconómico, supusieron un incremento notable de la polarización del ingreso, la erosión de los sectores medios y el empobrecimiento de grandes colectivos.

Por lo que hace a las características del proceso de cambio, a diferencia de lo que muchos teóricos pensaron, el paso de un sistema dictatorial a uno democrático fue fruto de múltiples cálculos estratégicos entre actores políticos a la vista de las "opciones contingentes" que se presentaron tras la erosión de los regímenes autoritarios y de la incontenible presión que ejercía la sociedad civil organizada demandando derechos y libertades.

Así, la apertura y democratización de los regímenes fue un proceso histórico con distintas fases - de liberalización, transición y consolidación-donde, en cada una de estas etapas entraban en escena una variedad de actores con diferentes partidarios, preferencias, cálculos, recursos y horizontes de temporalidad (O'Donnell, Schmitter y Whitehead, 1986). El desenlace final, en un contexto de permanente indefinición, a menudo fueron producto -tal como expuso Maquiavelo en el Principe-de la fortuna y la virtú que tuvieron cada uno de los actores en liza.

Fueron, en gran medida, las elites políticas y económicas los actores que desmantelarían los regímenes autoritarios y formularían, posteriormente, las "reglas de juego democrático” de los nuevos sistemas políticos (Higley y Gunther, 1992). Pero estos procesos pactados, que encarrilaron a los diversos países a cambios "controlados" y "tranquilos" de un sistema a otro, conllevaron múltiples lastres para el funcionamiento posterior de la democracia: los “amarres", garantías, pactos, borrones y cuentas nuevas y amnistías, perpetuaron la presencia de múltiples "enclaves autoritarios” en las recién inauguradas democracias (Torres Rivas, 1998).

$Y$ es que si bien el concepto de "contingencia" tiene la ventaja de poner el énfasis en las decisiones colectivas y en interacciones políticas, es preciso recordar que los procesos de cambio se desenvolvieron en un determinado marco de restricciones institucionales e históricas que acotaban las “opciones posibles” (Cohen,1994; Karl,1995). Ignorar esta premisa supondría pasar por alto - de buena o mala fe-que los regímenes autoritarios tuvieron una raison d'être y unas directrices, así como unos vencedores y unos vencidos.

Así las cosas, las debilidades institucionales de las "nuevas democracias" no se deben solamente a disfunciones de 
la "ingeniería institucional" (Linz y Valenzuela,1997) ni a la torpeza de las élites (Agüero y Torcal,1993). Hay causas más profundas: por primera vez en la historia de América Latina se observa la convivencia generalizada de regímenes democráticos con políticas que empeoran las condiciones de vida de amplias mayorías. Se trata de un tipo de reduccionismo democrático en el que no sólo pone en cuestión la competitividad efectiva de los procesos electorales (los procesos de Nicaragua en 1996, y de Guatemala o de México durante toda la década no son, precisamente, ejemplos de limpieza electoral) o la confección de la agenda que se discute en ellos, sino que también perpetúa situaciones -entre elección y elección- donde imperan la impunidad, la corrupción pública, la opacidad administrativa y la subordinación del poder judicial al ejecutivo (Vilas,1998a).

Efectivamente, la democratización es muy difícil si no va acompañada de una democratización de la sociedad y de una reducción de las profundas fracturas económicas y culturales que hoy cruzan muchos países latinoamericanos. La democracia es un régimen de integración en torno a valores y actitudes compartidas; y la concertación política es una quimera cuando el mercado margina y la cultura discrimina. $¿$ Es posible hablar en estas latitudes de una democracia que, desafiando la etimología, promueva la exclusión social y política? En todo caso, muchos teóricos han empezado a curarse en salud y han acuñado conceptos como democracia delegativa para definir este tipo de regímenes (O'Donnell, 1997: 287-303).

Finalmente, en cuanto al papel de los actores externos, es importante apuntar que el contexto internacional en que han florecido los regímenes democráticos es un mundo unipolar bajo la hegemonía norteamericana. El desplome del imperio soviético, el aislamiento de Cuba y la derrota en las urnas (previo acoso militar) de la experiencia sandinista, dejó sin coartada al discurso antidemocrático. Efectivamente -aunque sin terciar el fin de la historia- el modelo liberal democrático apareció no sólo como el único homologable, sino como el único posible. Quizás ello nos de la llave para interpretar el entusiasmo mostrado por las administraciones Bush y Clinton para con los regímenes democráticos. Ejemplo de ello es la invasión de Haití para reinstaurar al presidente derrocado Bertrand Aristide; la negativa a apoyar las veleidades golpistas de Jorge Serrano en Guatemala y la de los militares paraguayos contra el presidente civil Juan Carlos Wassmosi; las presiones ejercidas por la comunidad internacional sobre el régimen de Alberto Fujimori en Perú durante los meses posteriores a su toma de posesión en julio del 2000, y la cautela hacia la incierta "revolución bolivariana” encabezada por Hugo Chávez en Venezuela.

$¿$ De dónde proviene tanto entusiasmo para con la democracia? Hay quienes argumentan que en la actualidad la institucionalidad democrática es la única que garantiza la estabilidad política, canaliza pacíficamente las demandas de la ciudadanía y acota las posibles transformaciones a la "agenda de políticas” que imponen las instituciones económicas multilaterales (Castañeda,1996).

Ciertamente, es necesario repetir los enormes beneficios que han supuesto la reinstauración de las democracias representativas. Pero también cabe señalar que, en muchas latitudes, estas nuevas democracias no se han reinstaurado hasta que las elites domésticas percibieron la evaporación de cualquier modelo alternativo que pudiera cuestionar el statu quo, y hasta haber hecho efectiva la desaparición, exilio o desmoralización de los aquellos sectores que, en su momento, abogaron por un cambio político radical. Ahora falta por ver la actitud de las elites cuando, en las generaciones venideras, aparezcan nuevamente opciones políticas transformadoras que compitan electoralmente -y con ciertas posibilidades de ganar- en el marco institucional democrático.

Muchos de los que desconfían de la sinceridad de la conversión democrática de algunos sectores de las elites latinoamericanas argumentan que no hace falta ser demócrata para actuar como tal. Pero parece que la apuesta por el mercado como valor prioritario ha conllevado la "aceptación" de la democracia. Con todo, el grado de sinceridad de los "nuevos demócratas" es difícilmente verificable. Verificación que se dará si, en el futuro, los sectores dominantes aceptan la posibilidad de que una opción transformadora acceda al poder, haciendo efectivo el principio democrático de la "alternancia". Si es así podrá decirse que la democracia se ha consolidado definitivamente en el subcontinente. En caso contrario -como la mutación de la tradicional rivalidad entre blancos y colorados en las elecciones presidenciales de 1999 para cerrar el paso al candidato del Frente Amplio en Uruguay - cabría calificar a las reciente democracias como la reificación de una quimera. Definiendo este término de la misma forma que lo hace el diccionario de la Real Academia: "como aquello que se propone a la imaginación como posible o certero no siéndolo".

\section{EL CONSENSO DE WASHINGTON: HACIA UN MISMO MODELO ECONÓMICO}

Hasta mediados de la década de los ochenta, la mayoría de los grandes países de América Latina adoptaron una estrategia de desarrollo económico basado en la substitución de importaciones. Esta estrategia (que suponía una notable intervención de los poderes públicos en el proceso industrializador) se realizó desde una notable "diversidad": en algunos países el estado mantuvo un importante rol en la economía (ya fuera a partir de políticas social-reformistas, como en Venezuela y Costa Rica; o corporativistas como en Perú, Panamá, Cuba, Nicaragua y México), mientras que en otros se desarrollaron políticas monetaristas y librecambistas (como fue el caso, desde instituciones democráticas, en Colombia, o desde regímenes autoritarios, como en Chile o Guatemala).

Sería a partir de la década de los noventa cuando tanto las coordenadas institucionales como las socioeconómicas de todos los países acabarían por converger (Gomà, 1998). En esta década no sólo se llevaría a cabo una ola de democratización; sino que a nivel económico se abandonarían las estrategias estatistas y reguladoras para seguir dos directrices: la adopción de políticas neoliberales de corte fondomonetarista y la apertura de las economías hacia el exterior.

En cuanto a las políticas de apertura económica al mercado internacional cabe señalar la reactivación de viejos pro- 
yectos de integración económica regional (como el Mercado Común Centroamericano, MCCA, y el Pacto Andino), la aparición de nuevas iniciativas (como el Tratado de Libre Comercio, TLC, y Mercosur) y la discusión de proyectos para la creación de un mercado común a nivel hemisférico (el Área de Libre Comercio de las Américas, ALCA).

De todas las iniciativas, las más relevantes fueron los resultados de los dos grandes proyectos de integración comercial hemisférica -el TLC y el Mercosur-que actualmente ya son el primer y cuarto bloque comercial del mundo.

Los orígenes del Mercosur se remontan al Tratado de Asunción firmado por los gobiernos de Argentina, Brasil, Uruguay y Paraguay el 21 de marzo de 1991. Con ello, los cuatro países se comprometían a establecer un "mercado común con libre circulación de bienes, servicios y factores productivos". Posteriormente, el bloque ha firmado acuerdos de cooperación con Chile y Bolivia con el fin de ampliar su alcance en el futuro.

Por ahora, los resultados han sido exitosos: con una superficie de 12 millones de kilómetros cuadrados, más de 200 millones de habitantes y con una producción anual que ronda los 1000 millones de dólares, la región se encuentra en condiciones de acelerar su crecimiento económico. En este contexto, el intercambio de Argentina con sus socios pasó del 8 por ciento en 1986 de sus operaciones totales a casi el 30 por ciento a finales de la década de 1990. Para Brasil, esa misma relación pasó del 5 por ciento a casi el 20 por ciento. Paraguay y Uruguay, como naciones más pequeñas, compraron y vendieron aproximadamente la mitad de sus importaciones y exportaciones a los países del Mercosur. Este incremento del comercio en el interior del bloque produjo una duplicación del comercio internacional en los cuatro países entre 1990 y 1995 (Schvarzer,1998). Aunque las cifras para el Brasil y Argentina son todavía bajas (en comparación con la Unión Europeal), la evolución es tan rápida que se puede esperar un nivel elevado de dependencia mutua a inicios del siglo XXI.

Respecto a la implementación del Tratado de Libre Comercio, firmado por los gobiernos de los Estados Unidos, Canadá y México el primer día de enero de 1994, supuso la desaparición de barreras comerciales y de inversiones entre los tres países; y se contrajo el compromiso de eliminar progresivamente los aranceles agrícolas entre Canadá y los Estados Unidos hasta su desaparición en el año 1998 y en el año 2008 para México.

Este tratado aceleró la integración de las tres economías y el incremento de sus flujos comerciales. Pero si un país se benefició de ello, éste fue los Estados Unidos: a finales de la década, el 75 por ciento de las importaciones agropecuarias de México y de Canadá procedían de éste. Para ello, se establecieron mecanismos compensadores, sobre todo para México, que después de la crisis de enero de 1995, necesitó una importante ayuda financiera. A pesar de ello, a finales de los noventa el volumen de exportaciones de México se triplicó respecto a 1980 (Bulmer-Thomas, 1998: 445) y, ante ello, otros países del hemisferio -y Chile con particular insistencia- mantuvieron contactos para integrarse al TLC.

De todas formas, a pesar del aplauso generalizado hacia estas políticas, la participación latinoamericana en el comer- cio mundial seguía siendo cercano al 4 por ciento: menos de la mitad de la participación del subcontinente en la población mundial. A la vez, a finales de los noventa en varios países pequeños del subcontinente, como resultado de su vulnerabilidad a los descensos de los precios de sus bienes, aún no habían recuperado el nivel de exportaciones de 1980.

Así, los efectos de este proceso aperturista fueron contradictorios: la concentración geográfica de las exportaciones se incrementó; la participación norteamericana creció notablemente en muchas repúblicas; y la composición de las exportaciones continuó, en gran medida, basándose en los productos tradicionales (como el cobre chileno) o en recursos naturales "no tradicionales" (como el carbón en Colombia). En definitiva, las exportaciones de la región siguieron dependiendo básicamente de productos primarios, lo que hace que sus ingresos continúen siendo muy vulnerables a choques externos (Bulmer-Thomas, 1998: 447). A pesar de ello, este tipo de políticas no sólo se ha mantenido, sino que se han planteado nuevos proyectos en la misma dirección: en la Cumbre de las Américas, celebrada en Miami en el año 1994, 25 jefes de estado del hemisferio se comprometieron a crear para el año 2005 una área de libre comercio (el ALCA) que abarcará desde el territorio de Yukon hasta Tierra de Fuego.

Respecto a la adopción de políticas neoliberales de corte fondomonetaristas, cabe señalar que éstas se implementaron bajo la herencia de la "década perdida" (caracterizada por las restricciones de crédito impuesto por la crisis de la deuda y por el decrecimiento económico). Su aplicación supuso un giro de la gestión de la demanda a la incentivación de la oferta; y de la creación de excedente público a la consideración de los beneficios privados como el único factor creador de bienestar colectivo. Todo ello a la par de la reducción de los márgenes de maniobra nacional de todos los países debido a la rígida condicionalidad impuesta por el Banco Mundial y el Fondo Monetario Internacional.

Pero el nuevo modelo neoliberal no sólo afectó a las políticas económicas, también conllevó la desregulación masiva de los mercados de trabajo y la descapitalización de los servicios de salud, educación y vivienda social, sin que se generara ningún tipo de programa compensatorio en políticas de garantía de rentas. Al cabo de una década, los efectos de estas políticas han sido el incremento de la dualización social (Salama y Valier,1997). Según datos del BID y de la CEPAL alrededor de 200 millones de los 446 millones de habitantes del subcontinente son pobres, y el 20 por ciento míseros (Aznárez, 2000)

Donde se ha vivido este proceso de precarización con mayor gravedad ha sido en los países centroamericanos -con excepción de Costa Rica-. En el istmo el ajuste se llevó a cabo en una situación donde la relación media entre deuda externa y PIB doblaba la tasa latinoamericana ( 74 por ciento frente al 36 por ciento), y donde los términos de intercambio de los productos de la región se deterioron un 40 por ciento en los últimos 15 años. Ambas cosas en un contexto marcado por la posguerra, la reconstrucción y la desmovilización de los ejércitos insurgentes y la reducción de las Fuerzas Armadas (Cardenal y Martí,1998) 
El resultado de estas dos tendencias - la apertura económica hacia el exterior por un lado, y el desmantelamiento progresivo de la economía pública y la jibarización de las prestaciones sociales por otro- ha supuesto el golpe definitivo al modelo de estados "nacional-populares" construidos en el subcontinente entre los años cuarenta y los setenta. Este cambio de modelo ha supuesto el incremento de la polarización del ingreso entre los sectores más pudientes y el resto. Fenómeno que ha incrementado las paradojas propias de estas latitudes. Así, si bien a finales de los noventa aumentaba significativamente la pobreza en Buenos Aires (del 29'9 por ciento de la población en 1985 al 47 por ciento en 1995), en 1998 unos 300.000 jóvenes capitalinos asistieron a cinco conciertos de los Rollings Stones pagando un promedio de $50 \$$ la entrada (Vilas,1998b).

Precisamente por ello, a finales de siglo, el malestar de muchos también se ha hecho notar en Latinoamérica: asonadas callejeras en Caracas, motines en el noroeste argentino, huelgas, levantamientos indígenas y tomas de ciudades en Ecuador, marchas campesinas en el noreste brasileño, descomposición social en Colombia e inestabilidad permanente en los países centroamericanos, han sido noticias recurrentes. Ante ello, el humor negro también ha hecho de las suyas. Tal como expuso un sociólogo argentino (Vilas,1998b), mientras más de 90.000 personas eran evacuadas por las inundaciones provocadas por fenómeno climatológico de El Niño, una broma circulaba en los ambientes políticos. Ésta decía que "las inundaciones no eran porque el agua subiera, sino porque el país se hundía”. Posiblemente antes de terminar este apartado cabría retomar la frase con la que el economista Victor Bulmer-Thomas (1998) empieza su obra sobre la historia económica de América Latina: "Para el 30 por ciento que recibe el 5 por ciento un rayo de esperanza; para el 5 por ciento que recibe un 30 por ciento una advertencia".

\section{LA VIOLENCIA QUE NO CESA}

La década de los noventa empezó con buenas noticias: el proceso de paz para Centroamérica parecía encauzarse. La victoria de Violeta Barrios de Chamorro en las elecciones nicaragüenses de 1990 significó el fin de la agresión norteamericana y la desmovilización de la Contra. Poco después, en 1992, se sellaría en Chapultepec el fin de doce años de guerra civil en El Salvador. Ambos acontecimientos generarían una dinámica conciliadora que supondría la desactivación de uno de los conflictos regionales más críticos de la década anterior. Desactivación que llegaría a puerto con la progresiva desmilitarización de Honduras y, en 1996, con los acuerdos de paz de Guatemala.

A pesar de ello, ni la "pacificación” de América Central ni la desaparición de un mundo bipolar supuso el fin de la violencia en el subcontinente. Ésta mantendría su centralidad en la vida política y social de la región y se manifestaría a través de múltiples formas: permanecería viva la lucha armada (con las Fuerzas Armadas Revolucionarias de Colombia -FARC- y el Ejército de Liberación Nacional -ELN- en Colombia; Sendero Luminoso y el Movimiento
Revolucionario Tupac Amaru -MRTA- en Perú; los recontras y recompas en Nicaragua; y el EZLN, el ERP y el ERPI en México); estallarían guerras y tensiones fronterizas (Perú y Ecuador se enfrentarían por el dominio de la sierra del Cóndor en 1994; y Nicaragua se enemistaría con Costa Rica y Honduras por cuestiones territoriales en 1997 y 1999 respectivamente); muchos estados harían gala de amnesia y dejarían impunes los crímenes políticos perpetrados en la década anterior y; finalmente, la delincuencia común experimentaría un incremento exponencial.

Con todo, uno de los fenómenos más relevantes sería la transformación de la "lucha armada". Dejando a un lado el fenómeno de Sendero Luminoso en Perú (casi extinguido en 1992 con la detención de su líder Abimael Guzmán), la violencia política dejaría de ser un instrumento "revolucionario" para convertirse en un mecanismo para terminar negociando con el estado. El ejemplo más gráfico de ello fue el levantamiento chiapaneco, donde se observaron las pretensiones sectoriales del EZLN y en el carácter eminentemente táctico del recurso a las armas en el laberíntico conflicto colombiano.

Así, desde sus primeras declaraciones en la selva Lacandona, los zapatistas hicieron hincapié en demandas específicas: tierra para los campesinos, dignidad para los indígenas, democracia y elecciones libres para los mexicanos en general. A la vez que su portavoz, el Subcomandante Marcos, formuló que el EZLN no se planteaba derrocar por la vía armada el régimen, sino que usaba las armas para ayudar a quienes carecían de voz y voto. Este modelo peculiar de "movimiento armado" fue sui generis: su supervivencia dependía más del manto protector generado por la opinión pública nacional y foránea que por el calibre y la cantidad de la munición disponible.

En el resto de los casos, y con mayor énfasis en Nicaragua (1991-1992), El Salvador (1992-1993), en Guatemala (19961997), y en Colombia (desde 1999), los procesos de negociación se centrarían en las condiciones de inserción de los insurgentes en la vida civil y en la obtención de cuotas de poder (Marti,1998).

Otra cuestión ha sido la impunidad (por acción u omisión) con que se ha comportado, en determidos momentos, el estado. En cuanto a la acción, cabe destacar los episodios de la militarización de Chiapas y la masacre de Acteal en diciembre de 1997, la cobertura de acciones paramilitares en Colombia, el asesinato de monseñor Girardi (48 horas después de que encabezara la presentación pública del informe final del Proyecto para la Recuperación de la Memoria Histórica de Guatemala), o la ejecución sumaria de los miembros del MRTA peruano que secuestraron la embajada japonesa en 1997.

Respecto a la omisión, cabe destacar la política de olvido que muchos de los gobiernos civiles llevaron a cabo al tratar las violaciones sistemáticas a los derechos humanos que realizaron los regímenes autoritarios que les precedieron (Blixen,1998). Leyes de amnistía, de punto final, de obediencia debida, o la simple silenciación del tema en la agenda política, institucionalizaron la impunidad. Lo mismo ocurrió en América Central con la redacción de informes escritos por Comisiones de la Verdad, donde se desvelaron 
los hechos pero nunca se llegó a responsabilizar a los inculpados. A pesar de ello, las primeras "confesiones" de militares argentinos durante 1994 y 1995; y la apertura de enjuiciamientos a miembros de la Junta Militar argentina, a altos cargos de la policía política chilena (DINA), al dictador guatemalteco Efraín Ríos Montt, y al mismo general Augusto Pinochet, reabrieron con fuerza el tema de la memoria histórica. Ciertamente, se trata de fenómenos complejos y delicados: en ellos está en juego la estabilidad de las instituciones, los intereses de actores económicos relevantes y, sobre todo, el imaginario del país. En esta dirección, como dijo Habermas "en un país sin historia -o con su historia en disputa- el que logra dar contenido a la memoria, definir los conceptos e interpretar el pasado, gana el futuro".

De todas formas, el fenómeno más relevante y trágico de la década ha sido el acelerado incremento de la delincuencia callejera y de la violencia común, sobre todo entre colectivos de jóvenes. La aparición masiva de pandillas, bandas, gans o maras que emulan el bandalismo que sus homólogos realizan en los barrios periféricos de las ciudades norteamericanas como Los Ángeles o Detroit son un hecho cotidiano. Frente a ello, las autoridades generalmente han reaccionando con la instauración de facto de estados de emergencia o con la militarización de las conurbaciones más peligrosas.

En esta dinámica se ha constatado cómo las consecuencias socioeconómicas de las drásticas políticas de ajuste han supuesto un duro golpe para los colectivos más desemparados. En esta línea cabe señalar el fenómeno de los niños (y adolescentes) de la calle (Minujin, 1999). Y si bien es demasiado complejo para acotarlo en pocas líneas, es preciso exponer que los estratos más débiles de la sociedad no sólo han cargado con la peor parte del nuevo modelo, sino que han terminado por ganarse el estigma de ser uno de los colectivos más peligrosos, violentos y anómicos del nuevo mapa social latinoamericano.

\section{Y LOS CIUDADANOS: ¿PARA CUÁNDO?}

A pesar de lo expuesto en el epígrafe anterior, la realidad latinoamericana de los noventa también ha sido un espacio en el que han emergido manifestaciones portadoras de esperanza y creatividad, sobre todo, en el marco de la ciudadanía. Recobrados los derechos civiles en pácticamente todo el continente, ha emergido una galaxia de movimientos sociales y formaciones partidarias que, hasta entoces, habían permanecido en la clandestinidad.

Así las cosas, la vida política en democracia ha supuesto bastante más que la legalización de los partidos y la consolidación de instituciones representativas. Es más, al finales de la década, para muchos ciudadanos de estos países las organizaciones sociales, las organizaciones eclesiales y la prensa independiente gozaban de mayor confianza que las formaciones partidarias, la justicia o el Congreso: según los datos del Latinobarómetro de 1997 las primeras inspiran un grado medio de confianza (agregado para todo el subcontinente) del 47 por ciento frente al 18 por ciento que inspiraban las segundas.
A pesar de ello, el rechazo individual a alguno de los actores políticos presentes en los actuales sistemas políticos no ha supuesto el desprestigio del sistema democrático. Al contrario: el 61 por ciento de los ciudadanos preferían un sistema democrático frente al 17 por ciento que decían preferir uno de autoritario. Otra cuestión es el grado de satisfacción de los rendimientos de las "democracias realmente existentes". Tal como se observa en la tabla siguiente, sólo un 27 por ciento de los entrevistados decían estar satisfechos.

\begin{tabular}{|c|c|c|}
\hline & Prefiere la democracia & Grado de satisfacción \\
\hline Costa Rica & 80 & 51 \\
\hline Uruguay & 80 & 52 \\
\hline Chile & 54 & 27 \\
\hline Argentina & 71 & 34 \\
\hline Bolivia & 64 & 25 \\
\hline Panamá & 75 & 28 \\
\hline Venezuela & 62 & 30 \\
\hline Brasil & 50 & 20 \\
\hline Ecuador & 52 & 34 \\
\hline El Salvador & 56 & 26 \\
\hline Honduras & 42 & 20 \\
\hline Nicaragua & 59 & 23 \\
\hline Guatemala & 51 & 16 \\
\hline México & 53 & 11 \\
\hline Paraguay & 59 & 22 \\
\hline Perú & 63 & 28 \\
\hline Colombia & 60 & 16 \\
\hline América Latina & 61 & 27 \\
\hline
\end{tabular}

Fuente: Diamond (1998)

Las razones de esta aparente paradoja entre el apoyo al sistema político y el descontento hacia los rendimientos que éste genera pueden estar relacionados con los aspectos que hemos ido desgranando a lo largo del texto. Posiblemente, uno de los principales factores de esta lógica haya sido el recrudecimiento de la vida cotidiana de grandes sectores de la población.

Ha sido esta creciente dificultad para "resolver" y "salir adelante" lo que ha ido quebrando las esferas que anteriormente separaban lo privado de lo público. La profunda crisis económica, los despidos masivos de empleados públicos y los drásticos recortes de los servicios sociales ha supuesto que las decisiones tomadas en las esfera pública irrumpieran con fuerza en el ámbito de lo doméstico. Es a partir de este fenómeno que cabe comprender la activación de actores sociales que anteriormente se habían manifestado de forma subordinada a otros protagonistas de la acción colectiva.

Esta "politización" de la vida privada ha implicado necesariamente una redefinición de las relaciones entre la esfera de lo público y lo privado, creando una renovada capacidad de expresión de ciertos sujetos sociales: los llamados nuevos sujetos sociales. Se trata de actores agrupados en torno a identidades sociales básicas (como los movimientos de mujeres, de jóvenes, de indígenas, o confesionales), a intereses específicos (como las redes ecologistas o ambientalistas), o a necesidades elementales que es preciso satisfacer (como las asociaciones comunales o de pobladores, las agrupaciones de deplazados y desmovilizados, o las ollas comunales).

Durante esta década, la movilización de estos colectivos -con el objetivo de conseguir aquellos derechos que hasta 
entonces habían sido sólo nominales- ha dado como fruto el incremento de su sentimicnto de eficacia social y política; a la vez que ha aumentando su confianza en la organización y en las ventajas derivadas de trabajar y presionar unidos.

Así, antes de finalizar este texto, se podría afirmar que una de las características más relevantes de esta década que termina ha sido la progresiva recuperación (aunque no definitiva ni completa) del sentimiento de muchos habitantes de ser "ciudadanos de pleno derecho". Esta "recuperación" (que en algunos países ha sido un estreno), que ha sido el fruto de una larga una lucha, se ha librado gracias a la permanencia de un "imaginario" que visualiza un mundo mejor y más justo en el que aún persiste el mito de la posibilidad de crear países en los que todo el mundo tenga "un lugar bajo el sol". Será la pronta consecución de su precioso encuentro lo que nos indicará si esta década que finaliza pueda catalogarse como la de las oportunidades, o de las quimeras.

\section{BIBLIOGRAFÍA CITADA}

AgüERO, F. y TorCAL, M. (1993): "Élites, factores estructurales y democratización”. En: Revista de Estudios Políticos n 80: 329350.

ANÁREZ, J.J. (2000): “La pobreza crece en América Latina” en EL PAÍS, 13 de febrero de 2000.

Blixen, A. (1998): La operación Cóndor. Barcelona: Virus.

Bulmer-ThOMAS, V. (1998): La bistoria económica de América Latina desde la independencia. México: FCE.

Cardenal, A.S. y Martí, S. (eds.) (1998): América Central las democracias inciertas. Madrid: Tecnos.

CASTAÑEDA, J. (1993): The Utopia Unarmed. New York: Vintage.

- (1994) "América Latina y la terminación de la guerra fría: un ensayo sobre la frustración” en: LOWENTHAL, A. F. y TREverton, G. F. (eds.): América Latina en un nuevo mundo. México: FCE. pp. 40-82.

- (1995): ¿La última sorpresa? México: Aguilar.

Close, D. (1999): Nicaragua: The Chamorro Years. Boulder: Lynne Rienner.

Cohen, Y. (1994): Radicals, Reformers and Reactionaries. Chicago: The Chicago University Press.

Diamond, L. (1998): "Political Culture and Democratic Consolidation" Madrid: WP/118 Instituto Juan March.

FonT, J. (1996): Guatemala: ¿De la guerra a la paz? Barcelona: Edicions de la Casa de la Solidaritat.

González Briceño, H. (1999): “¡El triunfo de Chávez o la feria de las ilusiones!” Revista Viento Sur, n’ 46: 25-31.

Hagopian, F. (1996): Traditional Politics and Regime Change in Brasil. Cambridge: Cambridge University Press.

Higley, J. y Gunther, R. (eds.) (1992): Elites and Democratic Consolidation in Latin America and Southern Europe. Cambridge: Cambridge University Press.

Huntington, S. (1991): The Third Wave. Democratization in the late Twentieth Century. OK: University of Oklahoma Press.
KARL, T. (1995): "Dilemas de la democratización en América Latina” en: Reyna, J. L. (comp.): América Latina a fines de siglo. México: FCE. pp. 432-458.

KAY, B.H. (1995): Fujipopulism and the liberal State in Peru, 19901995. Durham: North Carolina University Press.

Kornblith, A. \& Levine, D. (1993): Venezuela: The Life and Time of the Party System. Working Paper Kellog Institute.

LEYVA, X. y ASCENCIO, G. (1996): Lacandona al filo del agua. México: FCE-CIEASAS-CIHMECH-UNAM-UNICACH.

Linz, J. J. y VAlenzuela, A. (eds.) (1997): La crisis del presidencialismo. 1. Perspectivas comparadas. Madrid: Alianza.

MARTí, S. (1997): Nicaragua: 1977-1996. La revolución enredada. Madrid: Libros de la Catarata.

- (1998): "La izquierda centroamericana: ¿Renacimiento o debacle?” en Cardenal, A. S. y Martí, S. (eds.) (1998): América Central: las democracias inciertas. Madrid: Tecnos. pp. 65-108.

Minujin, A. (1999): “¿La gran exclusión? Vulnerabilidad y exclusión en América Latina” en FILMUS, D. (comp.): Los noventa. Buenos Aires: FLACSO-EUDEBA. pp. 53-78.

O’Donnell, G. (1997): Contrapuntos. Ensayos escogidos sobre autoritarismo y democratización. Buenos Aires: Paidós.

O’Donnell, G. Schmitter, P. y Whitehead, L. (1986): Transiciones desde un gobierno autoritario. (4 vol.) Buenos Aires: Paidós.

PeELER, J. (1992): "Elite settlements and democratic consolidation: Colombia, Costa Rica and Venezuela” en: Higley, R. \& GUNTHER (eds.): Elites and Democratic Consolidation in Latin America and Southern Europe. Cambridge: Cambridge Uni versity Press. pp. 81-112.

RouQuié, A. (1984): El estado militar en América Latina. México: Siglo XXI.

Rovira Mas, J. (1988): Estado y política económica en Costa Rica, 1948-1970. San Pedro de Montes de Oca: Porvenir.

Rowland, M. (1998): Pugna de poderes. Quito: Documento de trabajo de CORDES.

Salama, P. y Valier, J. (1997): "De la pauvreté et des moyens de l'acrôte" en: Couffignal, G. ed. Amérique Latine. Tournant de siècle. Paris: Éditions La Découverte et Syros. pp. 69-75.

SChVARZER, J. (1998): "Mercosur: Perspectivas para la integración regional" en: www.nacla.org/span_ed/may_jun_98/8. btm

Starn, O., Degregori, C.I., Kirk, R. (1995): The Peru Reader Durham: Duke University Press.

TORRES-Rivas, E. (1989): “Authoritarian Transitions to Democracy in Central America” en: FlorA, J.L. \& TORRES-Rivas, E. (eds) Central America. Houndmilles: Macmillan. pp. 193-210.

- (1998a) "Los déficits democráticos en la posguerra" en: Cardenal, A.S. y Martí, S. (eds.) (1998): América Central las democracias inciertas. Madrid: Tecnos. pp. 331-352.

- (1998b): Del autoritarismo a la paz. Guatemala: FLACSO

VILAS, C.M. (1998a): "Democratización en los escenarios posrevolucionarios de Centroamérica" en: CARDENAL, A.S. y MARTí, S. (eds.) (1998): América Central las democracias inciertas. Madrid: Tecnos. pp. 281-329

- (1998b): "En la línea de fuego. El menemismo y la política de oposición en Argentina” en: www.nacla.org/span_ed/may_ jun_98/4.btm 


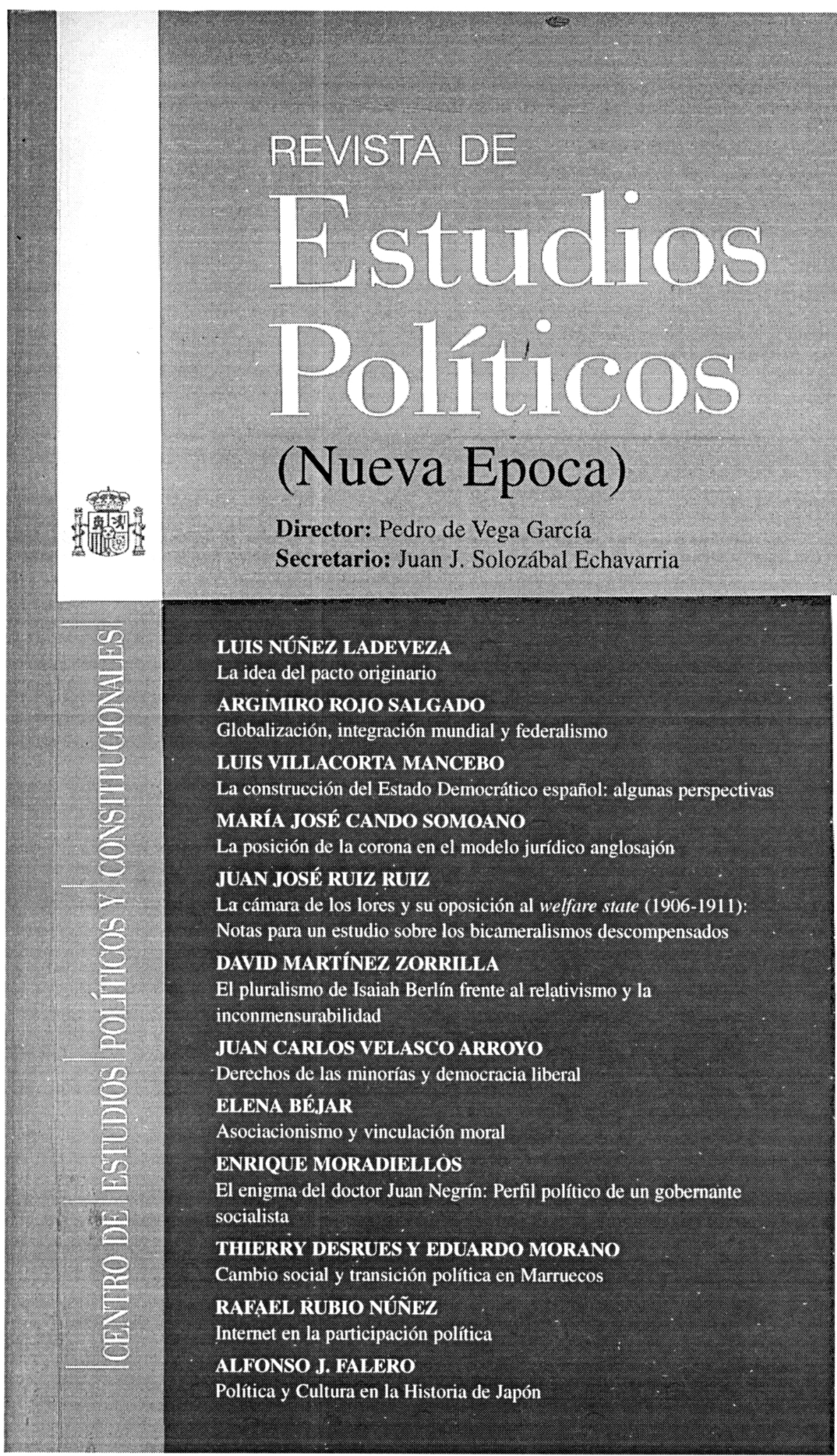

\section{9}

NUEVA ÉPOCA

Julio/Septiembre

2000

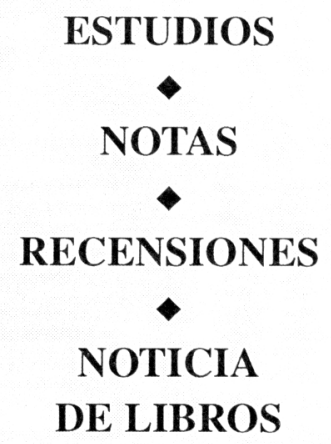

PRECIOS DE SUSCRIPCIÓN ANUAL

España

Extranjero

Número suelto España

Número suelto Extranjero
6.400,- Ptas. $-38,47 €$
$9.700,-$ Ptas. $-58,30 €$
1.800,- Ptas. - $10,82 €$
3.000,- Ptas. - $18,03 €$

Suscripciones y números:

CENTRO DE ESTUDIOS POLÍTICOS Y CONSTITUCIONALES

San Francisco de Sales, 6 28071 MADRID

Telefs. (34)91-4412700 - Fax (34)91-4410086 